Journal of Dental Science and Therapy

\title{
A-fodrinAutoantigen Detection in Saliva and on Salivary Ductal Cells in Sjögren Syndrome
}

\author{
Yan Wang ${ }^{1}$, Sean Parsel ${ }^{2}$, Alexander Shnyra ${ }^{3}$, Nicole Parrish ${ }^{4}$, Kyle Boyce ${ }^{1}$, Ying Liu ${ }^{5}$ and Carole McArthur ${ }^{1, *}$ \\ ${ }^{1}$ University of Missouri-Kansas City, School of Dentistry \\ ${ }^{2}$ Tulane University School of Medicine, Department of Otolaryngology \\ ${ }^{3}$ Kansas City University of Medicine and Biosciences, Department of Pharmacology and Biochemistry \\ 4Johns Hopkins Medical Institute \\ ${ }^{5}$ Eastern Tennesee State University
}

\begin{abstract}
*Corresponding author: Carole McArthur, M.D., Ph.D., Professor, Department of Oral and Craniofacial Sciences, University of Missouri-Kansas City School of Dentistry, 650 E 25th St, Kansas City, MO, 64108, USA; E mail: mcarthurc@umkc.edu
\end{abstract}

Article Type: Research, Submission Date: 23 June 2016, Accepted Date: 18 July 2016, Published Date: 03 August 2016.

Citation: Yan Wang, Sean Parsel, Alexander Shnyra, Nicole Parrish, Kyle Boyce, Ying Liu and Carole McArthur (2016) A-fodrinAutoantigen Detection in Saliva and on Salivary Ductal Cells in Sjögren Syndrome. J. Dent. Sci. Ther 1(2): 5-14. doi: https://doi.org/10.24218/ jdst.2016.07.

Copyright: @ 2016 Yan Wang, et al. This is an open-access article distributed under the terms of the Creative Commons Attribution License, which permits unrestricted use, distribution, and reproduction in any medium, provided the original author and source are credited.

\section{Abstract}

Background: Sjögren syndrome (SS) is an autoimmune exocrinopathy in which patients produce autoantibodies against the antigen $\alpha$-fodrin. In the murine model the antigen that elicits the antibody response is a $120 \mathrm{kDacleaved} \alpha$-fodrin fragment. In a human salivary gland (HSG) ductal cell in vitro model the $a$-chain of the protein fodrin is cleaved following TNF-induced apoptosis to yield a cleaved product. Cleaved $\alpha$-fodrin is presented on the cell surface suggesting a mechanism for antigen recognition in vivo as well as a potential antigen of value in diagnosis. The objective of this study was to test the hypothesis that cleaved $\alpha$-fodrin is expressed in minor salivary gland biopsies and saliva in vivo.

Methods: Nineteen patients with primary SS were recruited and provided plasma and a minor salivary gland biopsy. Nine of the 19 patients provided sufficient whole unstimulated saliva suitable for analysis. Saliva and minor salivary gland biopsies were also obtained from 16 healthy individuals without a history of autoimmune disease, and from 22 patients with HIV/AIDS. Biopsies were examined and graded histologically and with a monospecific antibody (ASP 1185) for detection of the cleaved $120 \mathrm{kD}$ fragment of $a$-fodrin by immunohistochemistry. Saliva was concentrated and subjected to Western blot analysis using an enhanced chemiluminescent detection system and by an antibody against the cleaved fragment of $\alpha$-fodrin. Plasma was also tested for autoantibodies against cleaved $\alpha$-fodrin using a commercially available ELISA.

Results: Seventy nine percent of patient saliva samples were shown to contain a $120 \mathrm{kDa}$ cleaved $\alpha$-fodrin protein on ductal epithelia in the minor salivary glands and 4 of the same patients had detectable cleaved $a$-fodrin in saliva. None of the saliva samples or minor salivary gland biopsies from 16 healthy controls or from 22 patients with HIV/AIDS contained detectable cleaved a-fodrin protein.
Conclusion: This is the first report of the cleaved $120 \mathrm{kDa}$ fragment of the autoantigen $\alpha$-fodrin in saliva. Confirmation in a larger number of patients at earlier stages of disease is necessary. Further studies could lead to the development of a diagnostic tool to monitor disease progression via a saliva sample.

Keywords: Cytokine, Apoptosis, Cleavage, a-fodrin, immunoglobulin, TNF, Sjögren syndrome.

\section{Introduction}

Sjögren syndrome (SS) is characterized bylymphocytic infiltration of the salivary and lacrimal glands by $\mathrm{CD} 4^{+} \mathrm{T}$ lymphocytes, loss or "drop out" of acinar secretory cells, and eventual fibrosis and destruction of the gland [1,2]. Sjögren syndrome is an autoimmune disease, producing a range of autoantibodiesand cytokines leading to apoptosis of salivary and lacrimal tissues [1-5]. Current diagnostic tests are unable to render a specific diagnosis of SS and thus there is a need for improved diagnostic tools. It would therefore be of value to identify a biomarker suitable for the early diagnosis and monitoring of tissue destruction. A more thorough understanding of the mechanism that leads to the destruction of salivary and lacrimal glands in SS may also improve the quality of life in patients and open new avenues for the development of novel diagnostic tools and therapies.

Many studies have demonstrated that apoptosis is involved in the potential mechanism for the development of autoimmune diseases [6-10]. The increase in proteolytic activity during apoptosis provokes degradation of cellular or nuclear proteins, some of which could act as autoantigens when presented to the immune system. We have shown this in the case of Sjögren syndrome type A (SS-A) and B (SS-B) antigens as well as cleaved $\alpha$-fodrin $[7,8]$ in vitro. In vivo, such autoantigens could elicit autoantibody production and contribute to the initiation and propagation of autoimmunity [3].Because apoptosis is a well-documented mechanism leading to salivary cell death, we 
Citation: Yan Wang, Sean Parsel, Alexander Shnyra, Nicole Parrish, Kyle Boyce, Ying Liu and Carole McArthur (2016) A-fodrinAutoantigen Detection in Saliva and on Salivary Ductal Cells in Sjögren Syndrome. J. Dent. Sci. Ther 1(2): 5-14. doi: https://doi.org/10.24218/jdst.2016.07.

hypothesized that the apoptotic products of salivary tissues may be detectable in the saliva of patients with SS. In patients with HIV/AIDS, the retrovirus or products also induces apoptosis, and patients may also suffer xerostomia due to diffuse infiltrative lymphocytosis syndrome (DILS).

The membrane-associated cytoskeleton protein fodrin (also known as non-erythroidspectrin) consists of $\alpha$ - and $\beta$-subunits of which the $\alpha$-subunit is highly conserved and is $90 \%$ identical among species [5].The function of fodrin is to provide internal structural support to the lipid bilayer of the cell membrane. Proteolysis of fodrin by caspases during apoptosis isinduced by a variety of stimuli and cytokines, notably tumor necrosis factor $a$ (TNF- $\alpha$ ) [11].Apoptotic cleavage of the $240 \mathrm{kDafodrin}$ at several sites can result in the generation of a $150 \mathrm{kDa}$ amino terminal, a $120 \mathrm{kDacarboxy}$ terminal, and a $35 \mathrm{kDa}$ fragment during TNF- $\alpha$ induced apoptosis $[4,10,12]$.In studies reported using the NFS/ sld mouse model of SS, the purified $120 \mathrm{kDa}$ fragment $\alpha$-fodrin antigen was shown to induce proliferative $T$ cell responses and the production of interleukin-2 and interferon- $\gamma$ (IFN- $\gamma$ ) in vitro [4]. Furthermore, neonatal immunization with the $120 \mathrm{kDa}$ antigen was shown to induce tolerance and prevent the development of autoimmune disease in the NFS/sld murine model. Sera from patients with SS and other autoimmune diseases may react positively with the purified $120 \mathrm{kDa}$ antigen but there is little known about the distribution of the antigen in tissues. There are several reports that have evaluated the diagnostic value of the homologous autoantibodies with a wide range of efficacy depending upon the criteria used for patient selection and technical issues but not the autoantigen. Based on the NFS/sld mouse model, results show that the $120 \mathrm{kDa}$ fragment of fodrin is only found in salivary tissue and is not detected in lung, liver, heart, kidney, pancreas, spleen, or brain. These results suggest that the immune response to $120 \mathrm{kDa} \alpha$-fodrin could be important in stimulating the initial development of primary SS [4]. Other studies carried out in human salivary gland (HSG) ductal and acinar cells in vitro suggest a potential mechanism of autoantibody formation by showing that $\alpha$-fodrin is cleaved following TNF- $\alpha$ induced apoptosis [7,10].Apoptosis yields a $120 \mathrm{kDa}$ cleaved protein that is mobilized from within cultured salivary ductal cells and presented on the cell surface. The underlying rationale for the present study is that if the $120 \mathrm{kDa}$ fragment of $\alpha$-fodrin is produced and mobilized to the salivary cell surface in vivo and expressed following apoptosis, the cleaved fragment of $\alpha$-fodrin may be expected to occur in saliva or detectable on salivary tissues obtained from patients with SS.

\section{Methods}

\section{Subject recruitment and sample collection}

Institutional Review Board approval from the University of Missouri-Kansas City and informed written consent was obtained from all individuals prior to this study. In the present study, tissues from 19 primary SS patients, 22 HIV/AIDS patients, and 16 healthy controls were examined. Patients with primary SS were selected using the classification system of the AmericanEuropean Consensus Group [13]. Patients were all under the care of a rheumatologist and were recruited through a local SS support group at St Luke's hospital in Kansas City and referred to the University of Missouri School of Dentistry dental clinic for this study. Patients with secondary SS were excluded due to the inability to standardize patient selection and testing, variation in diagnostic criteria applied and our inability to obtain sufficient numbers in each group. All patients with primary SS complained of xerostomia, had a history of Class III or IV Greenspan score from a labial salivary gland biopsy, keratoconjunctivitissicca with Schirmer's test of less than $4 \mathrm{~mm}$ and/or arthritis. These cases were well characterized, non-smokers, and all patients had at least one positive autoantibody (SS-A or SS-B) recorded previously. Saliva and plasma from healthy individuals seen in our dental clinic and from those with HIV/AIDS were also used as controls in this study. Controls were obtained from 8 healthy males aged 24-46 and 8 females aged 21-44 with no prior history of autoimmune disease or HIV/AIDS. Twenty-two patients (6 female aged 25-56 and 16 male aged 25-46) with a confirmed diagnosis of human immunodeficiency virus (HIV) infections were recruited from the University of Missouri-Kansas City dental clinic and Truman Medical Center.Two of the females and 7 of the males admitted to being smokers.

The histologic study also utilized archival biopsies confirming grading and lymphocytic focus score from 16 healthy controls reported previously and included in Table $1 \mathrm{a}$ and $1 \mathrm{~b}$ [8]. Sixteen HIV patients from whom saliva was available, had received a broad range of anti-retroviral drugs, including protease inhibitors, while 6 of the HIV patients had not. None of the HIV/AIDS subjects had reported objective symptoms of hyposalivation nor was parotid enlargement observed upon physical examination. Pathology results on archival salivary biopsies from HIV patients and healthy controls were not statistically different $(p>0.05)$ [8]. This was not surprising since most HIV patients were receiving anti-retroviral therapy.

\section{Salivary cell line and culture}

The HSG is a well-studied ductal epithelial cell line that was obtained from an irradiated, but histologically normal human submandibular gland [14].Although these cells exhibit an immortalized growth pattern, they retain an exocrine gland phenotype through expression of lactoferrin and amylase $[15,16]$. The HSG cell line has been used as a model system to study salivary gland function $[17,18]$.HSG cells, obtained originally from Dr. HyndaKleinman at the National Institute of Dental and Craniofacial Research (NIDCR), were cultured as follows and stored frozen in glycerol at passage 23-24 and later recovered for this study. Cells were cultured in Dulbecco's Modified Eagle Medium(DMEM) supplemented with 10\% fetal bovine serum, penicillin $(100 \mathrm{U} / \mathrm{mL}) /$ streptomycin $(100 \mu \mathrm{g} /$ $\mathrm{mL}$ )in a humidified atmosphere of $95 \%$ air and $5 \% \mathrm{CO}_{2}$ at 37 ${ }^{\circ} \mathrm{C}$. After $4 \mathrm{~h}$ culture in the presence of a combination of TNF- $\alpha$ (10 ng/mL) (R and D Systems, Minneapolis, MN) to stimulate apoptosis and cycloheximide (CHX) $(10 \mu \mathrm{g} / \mathrm{mL}$; Sigma-Aldrich, St. Louis, MO), $1 \times 10^{5}$ cells were harvested. Cells were dissociated with trypsin, harvested, and solubilized with gel loading buffer (62.5 mMTris- $\mathrm{HCl}, 2 \%$ SDS, 25\% glycerol, $0.01 \%$ bromophenol blue, $0.05 \% \mathrm{v} / \mathrm{v} 2$-mercaptoethanol, $\mathrm{pH} 6.8$ ). The post-apoptotic sample containing cleaved $\alpha$-fodrin was then incubated at $100{ }^{\circ} \mathrm{C}$ for $5 \mathrm{~min}$ prior to loading onto the gel as a marker for analysis by Western blot.

\section{Saliva collection}

Unstimulated saliva $(0.5-2.00 \mathrm{~mL})$ was collected from patients into a $50 \mathrm{ml}$ plastic centrifuge tube (Falcon) by expectorating saliva passively as it accumulated over a 20 minute period 
Citation: Yan Wang, Sean Parsel, Alexander Shnyra, Nicole Parrish, Kyle Boyce, Ying Liu and Carole McArthur (2016) A-fodrinAutoantigen Detection in Saliva and on Salivary Ductal Cells in Sjögren Syndrome. J. Dent. Sci. Ther 1(2): 5-14. doi: https://doi.org/10.24218/jdst.2016.07.

Table 1a: The results of cleaved $\alpha$-fodrin detected in saliva, anti-cleaved $\alpha$-fodrin autoantibodies in plasma, biopsy grade and focus score, and cleaved $\alpha$-fodrin detected by IHC

\begin{tabular}{|c|c|c|c|c|c|c|c|c|}
\hline SS & Gender & Age & Antigen, saliva & Anti-cleaved $\alpha$-fodrin & & Salivary grade & Biopsy focus score & IHC \\
\hline & & & & Plasma IgG, OD & Plasma IgA, OD & $0-4$ & $0-10$ & $0-3+$ \\
\hline 1 & $\mathrm{~F}$ & 57 & N.D. & 0.127 & 0.058 & 2 & 0 & 0 \\
\hline 2 & $\mathrm{~F}$ & - & N.D. & 0.373 & 0.191 & 3 & 0 & 0 \\
\hline 3 & $\mathrm{M}$ & 57 & pos. & 0.312 & 0.273 & 4 & 5 & $3+$ \\
\hline 4 & $\mathrm{~F}$ & 77 & pos. & 0.325 & 0.672 & 3 & 0 & $1+$ \\
\hline 5 & $\mathrm{~F}$ & 60 & Neg. * & 0.267 & 0.299 & 4 & 3 & $3+$ \\
\hline 6 & $\mathrm{~F}$ & - & N.D. & 0.152 & 0.172 & 3 & 0 & 0 \\
\hline 7 & $\mathrm{~F}$ & 59 & N.D. & 0.248 & 0.191 & 2 & 0 & 0 \\
\hline 8 & $\mathrm{~F}$ & - & Neg. * & 0.294 & 0.338 & 4 & 3 & $2+$ \\
\hline 9 & $\mathrm{~F}$ & 79 & N.D. & 0.194 & 0.182 & 2 & 0 & 0 \\
\hline 10 & $\mathrm{~F}$ & - & pos. & 0.268 & 0.45 & 4 & 4 & $2+$ \\
\hline 11 & $\mathrm{~F}$ & 69 & N.D. & 0.291 & 0.285 & 4 & 2 & $1+$ \\
\hline 12 & $F$ & 60 & N.D. & 0.153 & 0.272 & 3 & 0 & 0 \\
\hline 13 & $\mathrm{~F}$ & 58 & N.D. & 0.15 & 0.16 & 2 & 0 & 0 \\
\hline 14 & $\mathrm{~F}$ & 63 & Neg. * & 0.168 & 0.196 & 4 & 2 & $2+$ \\
\hline 15 & $M$ & 46 & pos. & 0.233 & 0.196 & 4 & 3 & $3+$ \\
\hline 16 & $\mathrm{~F}$ & 63 & Neg. * & 0.333 & 0.639 & 1 & 0 & 0 \\
\hline 17 & $\mathrm{~F}$ & 59 & Neg. * & 0.516 & 0.42 & 3 & 0 & $+/-$ \\
\hline 18 & $\mathrm{~F}$ & 61 & N.D. & 0.229 & 0.245 & 4 & 2 & N.D \\
\hline 19 & $\mathrm{~F}$ & - & N.D. & 0.38 & 0.349 & 0 & 0 & N.D \\
\hline
\end{tabular}

* Indicates slight positivity on the first gel but insufficient saliva to replicate. Only replicated samples were deemed positive

Table 1b: Similar results of healthy individuals confirming previous reports [8]

\begin{tabular}{|c|c|c|c|c|c|c|c|c|}
\hline Healthy & Gender & Age & Antigen, saliva & Anti-cleaved $\alpha$-fodrin & & Salivary grade & Biopsy focus score & IHC \\
\hline & & & & Plasma IgG, OD & Plasma IgA, OD & $0-4$ & $0-10$ & $0-3+$ \\
\hline 1 & $\mathrm{~F}$ & 21 & Neg & 0.222 & 0.027 & 0 & 0 & 0 \\
\hline 2 & $\mathrm{~F}$ & 26 & Neg & 0.175 & 0.227 & 0 & 0 & 0 \\
\hline 3 & $\mathrm{~F}$ & 34 & Neg & 0.188 & 0.285 & 1 & 0 & 0 \\
\hline 4 & $\mathrm{~F}$ & 40 & Neg & 0.245 & 0.288 & 3 & 0 & 1 \\
\hline 5 & $\mathrm{~F}$ & 21 & Neg & 0.019 & 0.189 & 2 & 0 & 0 \\
\hline 6 & M & 24 & Neg & 0.187 & 0.278 & 1 & 0 & 1 \\
\hline 7 & $\mathrm{~F}$ & 44 & Neg & 0.223 & 0.205 & 2 & 0 & 0 \\
\hline 8 & $\mathrm{~F}$ & 33 & Neg & 0.228 & 0.177 & 0 & 0 & 0 \\
\hline 9 & $M$ & 27 & Neg & 0.219 & 0.171 & 0 & 0 & 0 \\
\hline 10 & $M$ & 32 & Neg & 0.186 & 0.173 & 0 & 0 & 1 \\
\hline 11 & $M$ & 30 & Neg & 0.182 & 0.287 & 0 & 0 & 0 \\
\hline 12 & $\mathrm{~F}$ & 26 & Neg & 0.211 & 0.278 & 1 & 0 & 0 \\
\hline 13 & $M$ & 40 & Neg & 0.019 & 0.219 & 1 & 0 & 0 \\
\hline 14 & $M$ & 40 & Neg & 0.021 & 0.172 & 1 & 0 & 0 \\
\hline 15 & $M$ & 43 & Neg & 0.009 & 0.231 & 3 & 0 & $2+$ \\
\hline 16 & $M$ & 46 & Neg & 0.243 & 0.243 & 2 & 0 & 0 \\
\hline
\end{tabular}

following an oral rinse with fresh bottled water. Patients had not eaten for at least three hours prior to the collection which was carried out in the morning. Saliva samples were obtained from only 9 of 19 SS patients due to difficulties obtaining sufficient quantities of unstimulated saliva and its high viscosity in some patients. Plasma samples were obtained from all patients 
Citation: Yan Wang, Sean Parsel, Alexander Shnyra, Nicole Parrish, Kyle Boyce, Ying Liu and Carole McArthur (2016) A-fodrinAutoantigen Detection in Saliva and on Salivary Ductal Cells in Sjögren Syndrome. J. Dent. Sci. Ther 1(2): 5-14. doi: https://doi.org/10.24218/jdst.2016.07.

\begin{tabular}{|c|c|c|c|c|c|c|c|c|}
\hline HIV/AIDS & Gender & Age & $\begin{array}{l}\text { Antigen, } \\
\text { saliva }\end{array}$ & Anti-cleaved $\alpha$-fodrin & & Salivary grade & Biopsy focus score & IHC \\
\hline & & & & Plasma IgG, OD & Plasma IgA, OD & $0-4$ & $0-10$ & $0-3+$ \\
\hline 1 & M & 39 & Neg & ND & ND & 0 & 0 & 0 \\
\hline 2 & $\mathrm{~F}$ & 39 & Neg & ND & ND & 0 & 0 & 0 \\
\hline 3 & M & 46 & Neg & ND & ND & 1 & 0 & 0 \\
\hline 4 & M & 40 & Neg & ND & ND & 0 & 0 & 0 \\
\hline 5 & $\mathrm{~F}$ & 43 & Neg & ND & ND & 0 & 0 & 0 \\
\hline 6 & $\mathrm{~F}$ & 25 & Neg & ND & ND & 1 & 0 & 1 \\
\hline 7 & $\mathrm{~F}$ & 56 & Neg & ND & ND & 2 & 0 & 0 \\
\hline 8 & M & 30 & Neg & ND & ND & 0 & 0 & 0 \\
\hline 9 & $M$ & 44 & Neg & ND & ND & 0 & 0 & 0 \\
\hline 10 & $M$ & 34 & Neg & ND & ND & 0 & 0 & 1 \\
\hline 11 & $M$ & 41 & Neg & ND & ND & 0 & 0 & ND \\
\hline 12 & $M$ & 36 & Neg & ND & ND & 0 & 0 & 0 \\
\hline 13 & $M$ & 39 & Neg & ND & ND & 0 & 0 & 0 \\
\hline 14 & $M$ & 33 & Neg & ND & ND & 0 & 0 & 0 \\
\hline 15 & $\mathrm{~F}$ & 42 & $\mathrm{Neg}$ & ND & ND & 0 & 0 & ND \\
\hline 16 & $\mathrm{~F}$ & 43 & Neg & ND & ND & 1 & 0 & 0 \\
\hline 17 & $M$ & 45 & Neg & ND & ND & 0 & 0 & 0 \\
\hline 18 & $M$ & 34 & Neg & ND & ND & 0 & 0 & 0 \\
\hline 19 & $\mathrm{~F}$ & 42 & Neg & ND & ND & 0 & 0 & 0 \\
\hline 20 & $M$ & 42 & Neg & ND & ND & 0 & 0 & 0 \\
\hline 21 & $\mathrm{~F}$ & 47 & Neg & ND & ND & 0 & 0 & 0 \\
\hline 22 & $M$ & 36 & $\mathrm{Neg}$ & ND & ND & 0 & 0 & 0 \\
\hline
\end{tabular}

Table 1c: Patients with HIV/AIDS, all receiving antiretroviral therapy

Summary of Table 1a, 1b and 1c: The comparison between Sjögren's syndrome, healthy individuals and patients with HIV/AIDS

\begin{tabular}{|c|c|c|c|c|c|c|}
\hline & $\begin{array}{l}\text { sample } \\
\text { size (n) }\end{array}$ & $\begin{array}{c}\text { algG }(U / m L) \\
\text { mean (std. } \\
\text { dev) }\end{array}$ & $\begin{array}{c}\text { algA }(\mathrm{U} / \mathrm{mL}) \\
\text { mean (std. } \\
\text { dev) }\end{array}$ & $\begin{array}{c}\text { bSalivarygrade } \\
\text { Median (interquartile) }\end{array}$ & $\begin{array}{c}\text { bBiopsy focus score } \\
\text { Median (interquartile) }\end{array}$ & $\begin{array}{c}\text { ' } \mathrm{IHC} \\
\text { Median (interquartile) }\end{array}$ \\
\hline $\begin{array}{l}\text { Sjögren Syndrome } \\
\text { (reference) }\end{array}$ & 19 & $0.26(0.10)$ & $0.29(0.16)$ & $3(2-4)$ & $0(0-3)$ & $0.5(0-2)$ \\
\hline Healthy & 16 & $0.16(0.09)^{* *}$ & $0.22(0.07)$ & $1(0-2)^{* * *}$ & $0(0-0)^{*}$ & $0(0-0.75)$ \\
\hline HIV/AIDS & 22 & $\mathrm{~N} / \mathrm{A}$ & N/A & $0(0-0)^{* * *}$ & $0(0-0)^{* *}$ & $0(0-0)^{*}$ \\
\hline
\end{tabular}

Note: $* p<0.05, * * p<0.01, * * * p<0.0001$

a. T-test for two independent groups.

b. $\quad$ Man-Whitney U test.

* Indicates slight positivity on the first gel but insufficient saliva to replicate. Only replicated samples were deemed positive

except one individual with SS. Due to these limitations, 9 saliva samples, 17 plasma samples, and 17 biopsies were analyzed for the presence of cleaved $\alpha$-fodrinautoantigen in saliva and minor salivary gland parenchyma.

\section{Western blot analysis}

Whole saliva from SS patients, patients with HIV/AIDS and controls was centrifuged (5,000 rpm, $10 \mathrm{~min})$ and the supernatant samples were aliquot and frozen at $-85{ }^{\circ} \mathrm{C}$ until Western blot analysis. Salivary samples were thawed and placed in Millipore ultracentrifugation tubes and centrifuged at 5,000 rpm for $2 \mathrm{~h}$ at $4{ }^{\circ} \mathrm{C}$ until the samples were concentrated to a volume of 50 $\mu \mathrm{L}$. 2X gel loading buffer ( $\mathrm{pH}$ 6.8) was mixed with samples and incubated at $100{ }^{\circ} \mathrm{C}$ for $5 \mathrm{~min}$.Samples were separated by electrophoresis on 10\% SDS-PAGE gels with running buffer (25 mMTris, 19.2 mMglycerine, 0.1\% SDS, $\mathrm{pH}$ 8.3) and the proteins were transferred to a Hybond-P membrane (Amersham Pharmacia Biotech Inc, Piscataway, NJ) with Tris/glycine buffer (20\% methanol). After protein samples was transferred to the membrane, the membranes were blocked with $5 \%(\mathrm{w} / \mathrm{v})$ skimmed milk powder in TBS $(20 \mathrm{mMTris}, 500 \mathrm{mMNaCl}, \mathrm{pH}$ 7.5) and then probed with a 1:1000 primary monospecific antia-fodrin antibody (Chemicon International, Inc., Temecula, CA) diluted in TTBS (0.05\% Tween). Following washing with TTBS, bound antibodies were detected using a peroxidase-conjugated anti-mouse IgG (Pierce, Rockford, IL). After further extensive washing with TTBS, peroxidase reactivity was detected using chemiluminescence (Pierce, Rockford, IL). Densitometry of the 
Citation: Yan Wang, Sean Parsel, Alexander Shnyra, Nicole Parrish, Kyle Boyce, Ying Liu and Carole McArthur (2016) A-fodrinAutoantigen Detection in Saliva and on Salivary Ductal Cells in Sjögren Syndrome. J. Dent. Sci. Ther 1(2): 5-14. doi: https://doi.org/10.24218/jdst.2016.07.

immunoblots was performed with a GS-250 molecular imaging system (Bio-Rad, Hercules, CA).

\section{Plasma collection and analysis}

Plasma samples were obtained from all patients to detect autoantibodies targeting cleaved $\alpha$-fodrin using an ELISA. ELISA was performed according to the manufacturer's recommendations (Genway Biotech, Inc. San Diego, CA 92121). Positivity for anti$\alpha$-fodrinIgG and IgA in this assay was established at a cut-off value of $6.25 \mathrm{U} / \mathrm{mL}$ by the manufacturer and results read on a microplate reader (Bio-Rad, Hercules, CA) were reported minus the value for the blank wells.

\section{Immunoperoxidase assay}

Labial minor salivary gland biopsies were fixed for 4 hours or overnight in $10 \%$ buffered formalin, dehydrated in graded alcohol, embedded in paraffin, sectioned at $5 \mu \mathrm{m}$, stained with hematoxylin and eosin and graded histologically for all patients as previously described [8]. Immunohistochemistry to detect cleaved $\alpha$-fodrin in minor salivary gland biopsies was performed via the immunoperoxidase assay following the manufacturer's instructions (Vector Labs, Burlingame, CA). The primary antibody was a rabbit polyclonal antibody (2121 Asp 1185) recognizing the cleaved fragment of human $\alpha$-fodrin (Cell Signaling Technology, Beverly, MA, USA) and a peroxidaselabeled secondary anti-rabbit IgG (\#7074) with IgG controls. The primary antibody does not recognize full-length $\alpha$-fodrin, only the cleaved product. To detect cleaved $\alpha$-fodrin, specimens were rehydrated and washed in PBS prior to application of the immunoperoxidase assay as previously reported. Briefly, to unmask and expose antigens, sections were initially heated in $10 \mathrm{mM}$ sodium citrate buffer ( $\mathrm{pH}$ 6.0) for $2 \mathrm{~min}$ in a microwave at full power followed by $20 \mathrm{~min}$ of cooling. Endogenous peroxidase was quenched with $0.3 \% \mathrm{H}_{2} \mathrm{O}_{2}$ in $\mathrm{PBS}$ for $10 \mathrm{~min}$ and sections were blocked with Blocking Solution provided in the kit. Slides were then subsequently reacted with polyclonal antibodies (1:100) specific for cleaved $\alpha$-fodrin (Asp 1185, Cell Signaling Technology, Beverly, MA, USA) and incubated overnight at room temperature. Next, after three further washes, sections were incubated for $2 \mathrm{~h}$ with a peroxidase-labeled secondary rabbit anti-mouse antibody (Zymed Laboratories Inc., San Francisco, CA) and color development was achieved by incubation for 1 to $5 \mathrm{~min}$ with diaminobenzidinetetrahydrochloride (DAB) reagent. Slides were counterstained with hematoxylin solution and excess hematoxylin was washed away with deionized water. Sections were finally dehydrated in graded alcohol followed by two xylene washes before they were also photographed using a TE300 photomicroscope (Nikon Instruments Inc., Melville, NY). Counting of immunostained cells was performed on salivary gland tissue samples containing ducts, acini, and lymphocytic infiltrates from SS patients and healthy controls without lymphocytic infiltrates by reacting tissue sections with polyclonal antibodies specific for cleaved $\alpha$-fodrin using a modification of the method described by Ohlsson et al. [2].

\section{Statistical analysis}

Based on the property of continuous variables, and that each SS and control individual sample contained both an anti- $\alpha$-fodrin ELISA $\operatorname{IgA}$ and $\operatorname{IgG}$ result, the reliability of $\operatorname{IgA}$ and $\operatorname{IgG}$ was measured with Pearson's correlation using criteria for strength of correlation: small (0.1) medium (0.3) large (0.5).A paired t-test was applied to detect the difference between IgA and IgG and t-tests for two independent groups were used to determine whether there was a significant difference between the positive and negative ELISA results for IgA and IgG. Levene's test was applied to detect equality of variances in this test. Meanwhile, a t-test was also used to identify whether the difference of antia-fodrin (IgG and IgA) exists between Sjögren Syndrome and healthy individuals (these data were not available for HIV/AIDS patients). Spearman's rank correlation was used to determine the association of $\alpha$-fodrinautoantigen IHC with salivary grade and biopsy focus score since they are ordinal variables.The Mann-Whitney U test was applied to detect whether Sjögren Syndrome is different from healthy individuals and HIV positive individuals with respect to salivary grade, biopsy focus score and IHC. Tukey's post hoc test was used to identify the pairwise significance of image band $\alpha$-fodrindensity (continuous variable) results for controls, SS-positive, and SS-negative groups after the overall significance was determined bya one-way ANOVA. Data were analyzed using SPSS ${ }^{\circledast}$ statistical software, version 15.0 (SPSS Inc., Chicago, IL, USA). A p-value of $<0.05$ was used to indicate statistically significance.

\section{Results}

\section{Salivary $\boldsymbol{a}$-fodrin antigen}

Western blot analysis of the salivary samples from the 9 saliva specimens obtained from SS patients revealed that $7(77.0 \%)$ of 9 individual saliva specimens contained the cleaved 120 $\mathrm{kDa} \alpha$-fodrin fragment. Three of these were barely visible on the preliminary gel; however, and there was insufficient sample to replicate them. Of the remaining four samples which were replicated, all were positive by western blot. Figure 1 shows a typical positive example and Figure 2a compares the results of the densitometry by image analysis. Figure $2 \mathrm{~b}$ is a bar graph comparing the mean alpha fodrinautoantigen levels detected in saliva samples from the 16 healthy individuals with the 9 patients with SS.Cleaved $\alpha$-fodrin was not detected in saliva from the 22 HIV/AIDS patients tested (data not shown). The positive control for the Western blot analysis consisted of the cleaved products of the HSG cell line stimulated by TNF- $\alpha$ in vitro by methods previously reported $[7,10]$. The Western blot of the cleaved products of HSG TNF-induced apoptosis showing cleaved $\alpha$-fodrin, PARP and procaspases, is presented in Figure 4.

\section{Immunohistochemistry}

Figure 1 shows the cleaved $\alpha$-fodrin product, which was also detected by immunohistochemistry in biopsies of 8 of 16 SS (50\%) patients tested. Immunoperoxidase staining (IHC) was primarily associated with ductal cells and occasional infiltrating CD4+ T lymphocytes in SS sections of minor salivary gland biopsies confirming previously published research [10].

Figure 3 is a photomicrograph that shows representative minimal staining of $a$-fodrin in a minor salivary gland biopsy from a healthy patient (Fig. 3a) and 2+ staining in diseased salivary tissue from an SS patient (Fig 3b). In sections from SS patients in Fig. 3b, cleaved apoptotic product, a-fodrin, is strongly associated with ductal (D) and acinar (A) epithelia. Counting of labeled ductal, acinar, and infiltrating mononuclear cells by two observers showed some variation in staining of ductal cells between patients $(41 \%, \mathrm{SD}=18.0 \%)$ and a significant difference $(\mathrm{p}<0.001)$ between the mean of SS patients compared with 
Citation: Yan Wang, Sean Parsel, Alexander Shnyra, Nicole Parrish, Kyle Boyce, Ying Liu and Carole McArthur (2016) A-fodrinAutoantigen Detection in Saliva and on Salivary Ductal Cells in Sjögren Syndrome. J. Dent. Sci. Ther 1(2): 5-14. doi: https://doi.org/10.24218/jdst.2016.07.

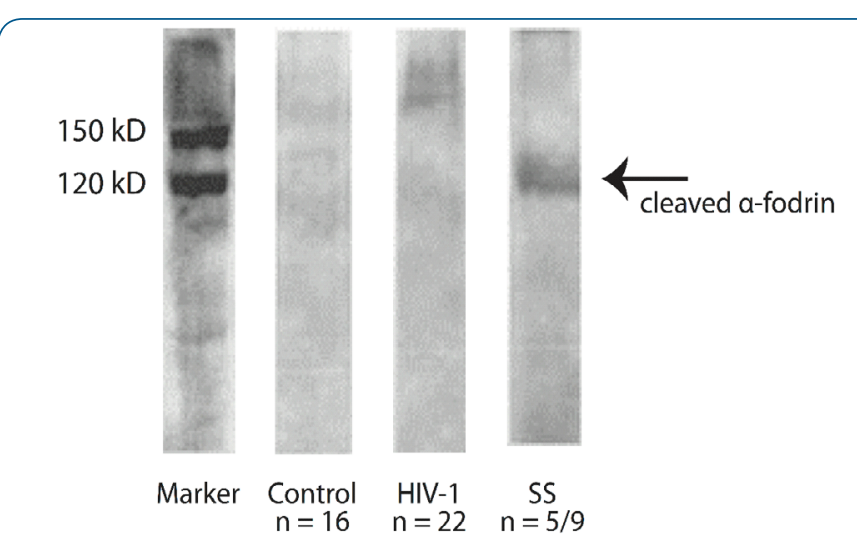

Figure 1: Cleaved $\alpha$-fodrin autoantigen present in Sjögren syndrome samples.

The left lane contains MW marker of cleaved $\alpha$-fodrin. Apoptotic products fodrin (220 kDa), $\alpha$-fodrin (150 kDa), and cleaved $\alpha$-fodrin (120 $\mathrm{kDa})$ are detected in the right lane. As seen by the positive band in lane 4 (right), cleaved $120 \mathrm{kDa}$-fodrin, which is a substrate of caspase 3 , is detected in saliva samples from 4 SS patients. None of the 22 HIV patients or 16 healthy controls had detectable cleaved $\alpha$-fodrin in their saliva. Saliva from 4 of the 9 SS patients contained clearly detectable cleaved $120 \mathrm{kDa}$ fragment as shown above as opposed to intact $\alpha$-fodrin suggesting that this is cleaved in ductal cells and released from the ductal cell surface into the salivary duct and oral cavity. Saliva from an additional SS patient was also positive but produced insufficient saliva to be replicated and thus was included with the negative SS samples in the image analysis in Figures $2 a$ and $2 b$

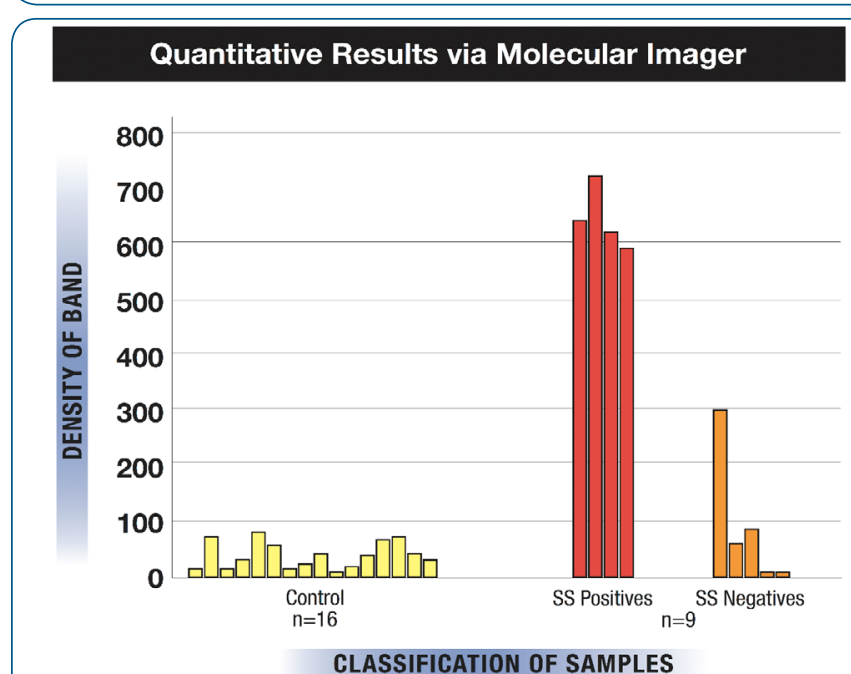

Figure 2a: The relative density of positive bands detected by western blot in SS (red bars), negative (orange) and healthy patients (yellow) compared by image analysis

healthy controls $(19 \%, \mathrm{SD}=8.0 \%)$. In the case of acinar cells, $27 \%(\mathrm{SD}=11.0 \%)$ stained positively in SS and in $11 \%(\mathrm{SD}=$ $6.0 \%)$ of healthy controls, a difference which was also significant $(\mathrm{p}<0.001)$. In the case of staining of the infiltrating lymphocytes, $31 \%$ (SD $=14 \%$ ) of lymphocytes were stained in patients with SS, while $12 \%$ of lymphocytes were stained in controls $(\mathrm{SD}=3 \%)$. This difference between SS and healthy controls was significant $(\mathrm{p}<0.001)$.

Plasma anti- $\alpha$-fodrin autoantibodies in primary SS patients (Table 1a and 1b)

Analysis of plasma samples for anti- $\alpha$-fodrin antibodies was carried out in 19 SS patients and 15 had IgG levels greater than those from healthy control patients. Plasma from 10 patients $(52.6 \%)$

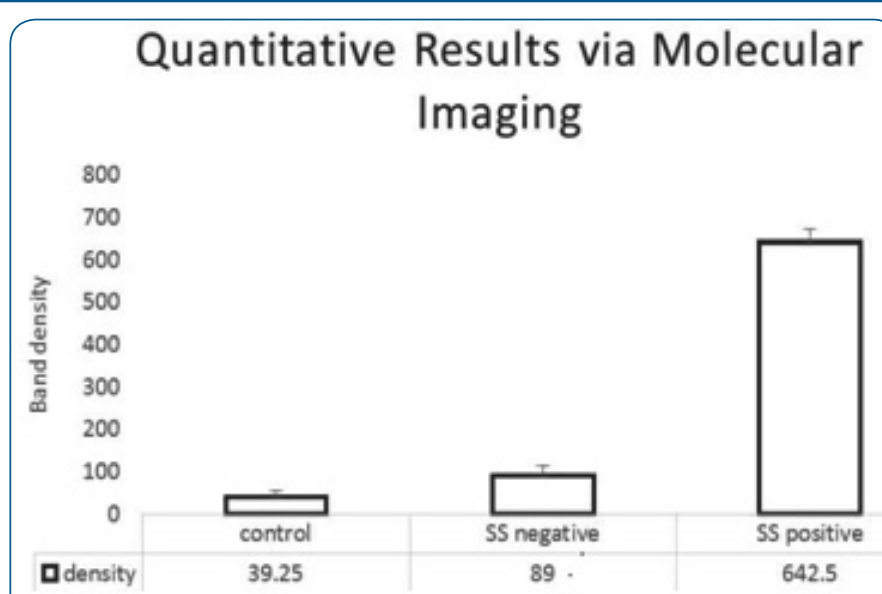

Figure $\mathbf{2 b}$ : A bar graph comparing the means of $\alpha$-fodrin detected in saliva from SS patients $(n=4)$, SS patients where $\alpha$-fodrin was not detected $(n=5)$, compared with saliva from healthy controls $(n=16)$

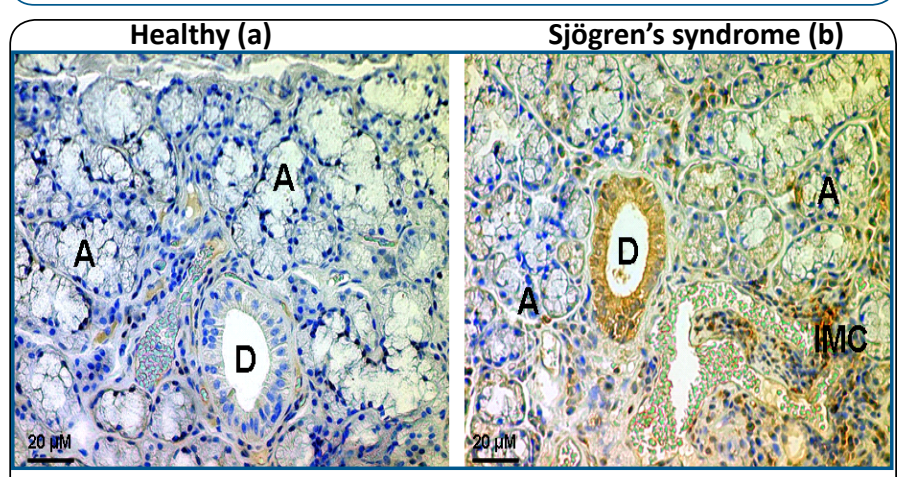

Figure 3: Photomicrographs of minor salivary glands showing cleaved $\alpha$-fodrin immunostaining of tissues from a healthy individual (Fig. 3a) and a patient with SS (Fig. 3b). Cleaved $\alpha$-fodrin staining (tan shade) was detected in situ using immunohistochemistry and immunoperoxidase staining. In SS (Fig. 3b), cleaved $\alpha$-fodrin autoantigen is strongly expressed on the ductal epithelium (D), on sporadic acinar cells (A) and strongly associated with infiltrating mononuclear cells (IMC). Cleaved $\alpha$-fodrin autoantigen was rarely detected in healthy control salivary gland biopsies or those with HIV/AIDS

had detectable levels of anti- $\alpha$-fodrin IgA. In all patients, the IgA levels ranged from 0.0 to $12.4 \mathrm{U} / \mathrm{mL}$. Further, $10 / 19$ (53\%) patients provided plasma with elevated levels of anti- $\alpha$-fodrinIgG. Antibody concentration ranged from 0.0 to $14.5 \mathrm{U} / \mathrm{mL}$. Of the 7 patients who produced adequate quantities of saliva suitable for detection of cleaved $\alpha$-fodrin by Western blot and who also had ELISA performed on plasma to determine autoantibodies, only 4 of the 7 saliva samples tested had detectable levels of cleaved $\alpha$-fodrin antigen by Western blot. Of these 4 patients, one patient produced both classes of plasma autoantibodies (both IgA and IgG) specific for cleaved $\alpha$-fodrin antigen. Saliva from 2 of the remaining 3 patients (67\%) contained no detectable levels of cleaved $\alpha$-fodrin protein in saliva but all 3 produced detectable levels of both IgA and IgG anti- $\alpha$-fodrin antibodies. By contrast, 16 of 17 SS patients had a positive biopsy (histologic Chisholm and Mason grade $>2+$ ) and when evaluated for the presence of cleaved $\alpha$-fodrin antigen in biopsy sections stained by immunohistochemistry, 8 were positive at varying levels with staining primarily associated with the ductal epithelium (Figure 3).

\section{Results of Statistical analysis}

IgA and IgG and $\alpha$-fodrin are moderately correlated with a Pearson's correlation coefficient of 0.506 . A paired test indicated 
Citation: Yan Wang, Sean Parsel, Alexander Shnyra, Nicole Parrish, Kyle Boyce, Ying Liu and Carole McArthur (2016) A-fodrinAutoantigen Detection in Saliva and on Salivary Ductal Cells in Sjögren Syndrome. J. Dent. Sci. Ther 1(2): 5-14. doi: https://doi.org/10.24218/jdst.2016.07.

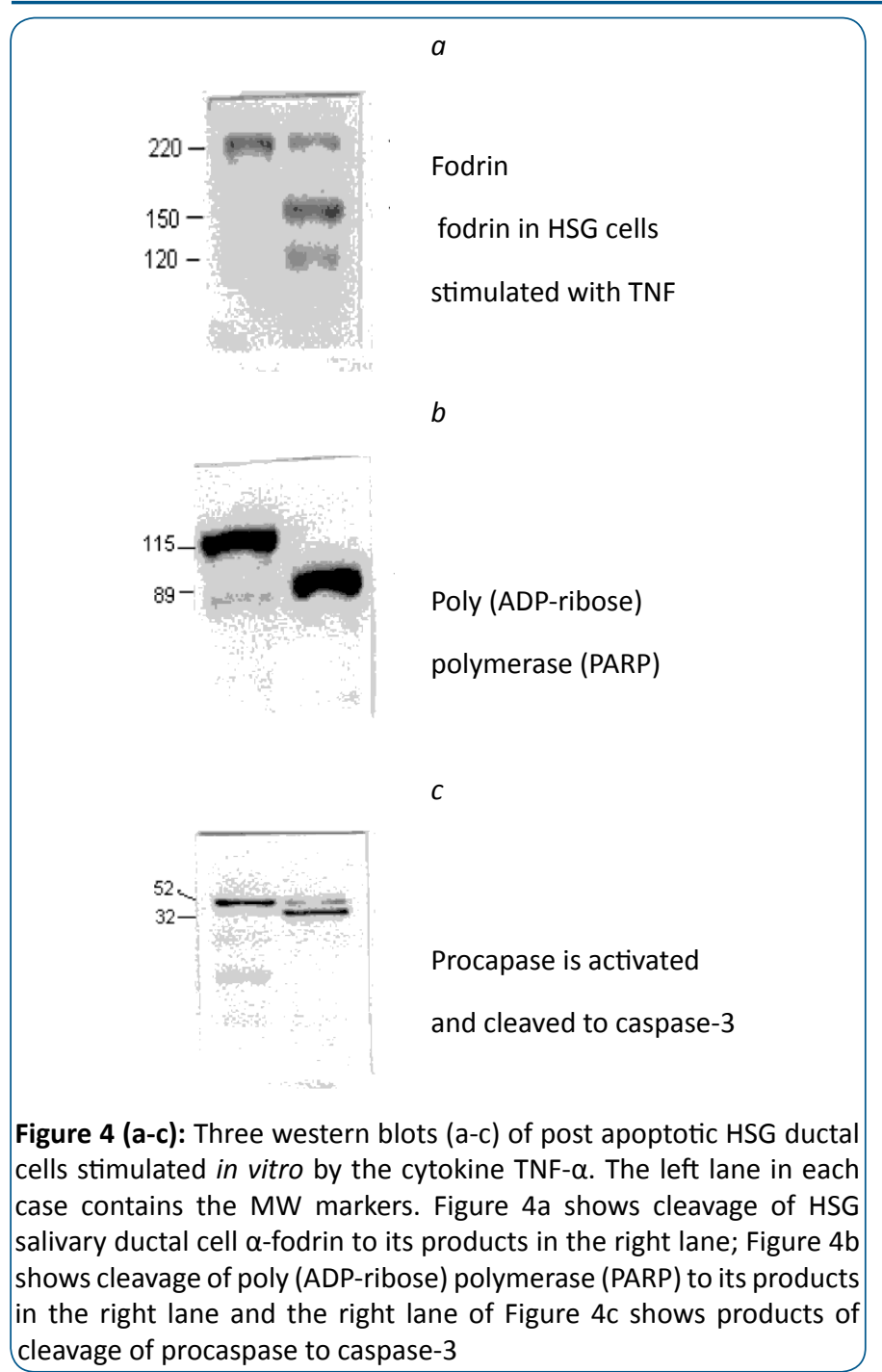

there was significant difference between ELISA IgA and IgG ( $\mathrm{p}$ $=0.048$ ) autoantibody levels. No significant difference was found between positive and negative ELISA IgA $(\mathrm{p}=0.163)$ and ELISA $\operatorname{IgG}(\mathrm{p}=0.062)$ values which may be due to a small sample size. A strong Spearman's correlation (0.864) of a-fodrinautoantigen IHC expression was detected with salivary gland disease grade and biopsy focus score in Sjögren syndrome patients and IgG, salivary grade and biopsy focus scorewere significantly different between healthy individuals and those with SS (Table 1); similarly, HIV/AIDS patient were also significantly different from patients with SS with respect to salivary grade, biopsy focus score and IHC (Table 1). Tukey's post hoc test indicated the density of the image band detected in saliva of SS patients with a positive western blot were significantly greater than those SS patients with a negative western blot or control groups. As expected, there was no significant difference between SS patients with a negative western blot and the healthy control group (Figure $2 \mathrm{~b}$ ).

\section{Discussion}

Sjögren syndrome (SS) is a systemic autoimmune disease with an unknown mechanism but which has been associated with the production of a range of autoantibodies and autoantigens. Most of the autoantibodies have not been directly related to cell damage in specific tissues although autoantibodies have been detected in salivary gland tissue, they are not considered the cause of salivary gland destruction.
In the current study, we determined the presence of both plasma autoantibodies in SS patients using an ELISA and a-fodrinautoantigen in saliva from the same patients, using Western blot analysis with molecular imaging and confirmed with a specific monospecific antibody by immunohistochemistry on minor salivary gland biopsies. All patients received a minor salivary gland lip biopsy to grade the level of disease histologically and to detect cleaved $a$-fodrinautoantigen expressed in both saliva and minor salivary gland tissues. This was a small study compromised by the inability of many of the recruited patients to produce sufficient saliva suitable for analysis by the western blot method. This was not surprising since most of the SS patients were post-menopausal women, which highlights the lack of sensitive assays available to detect salivary gland damage early during the course of the disease. However, of importance, the cleaved $\alpha$-fodrinautoantigen fragment was demonstrated semiquantitatively in salivary gland parenchyma of $8 / 16$ patients by immunohistochemistry and detected in the saliva of $4 / 9$ of the same patients tested. The remaining 10 patients produced insufficient saliva for analysis by the described methods. This finding supports evidence from previous studies that the cleaved $120 \mathrm{kDa} \alpha$-fodrinautoantigen detected in saliva is related to the level of apoptotic cell death and grade of disease in the salivary glands, and as such, this autoantigen, not the autoantibody, may be a useful marker of cell damage $[5,7,8,10]$. As expected, and shown by multiple previous studies, the autoantibodies against the cleaved $a$-fodrinfragment are of low diagnostic sensitivity, although, in support of our mechanistic immunologic hypothesis, all patients who produced a positive IgG or IgA autoantibody, also demonstrated the presence of the autoantigen in the salivary tissues by immunohistochemistry [19].

Accumulating evidence shows that at least one mechanism of salivary gland destruction involves apoptosis although the specific pathway has not been confirmed in vivo. Our previous results supported the role of $\alpha$-fodrin as one of several autoantigens associated with SS and suggested a potential mechanism. We have shown by cell fractionation and immunofluorescence that the $120 \mathrm{kDa}$ a-fodrin fragment cleaved from fodrin is relocated to the surface of apoptotic HSG cells in vitrowhen stimulated by TNF- $\alpha[7,10]$.It is also noteworthy from the current study that only the cleaved form was detected in saliva. This finding is consistent with presumed mechanism and suggests that cleavage occurs at the level of the salivary ducts probablybefore secreted into saliva. It may be insightful mechanistically to evaluate SS-A, SS-B, caspase 3 protein expression in concert with cleaved a-fodrin in saliva, especially using a highly sensitive plasmon grating nanotechnology [20], which has been recently reported for infectious disease detection, or mass spectrometry. In this way, small volumes of saliva could be evaluated for multiple antigens simultaneously.

The detection of cleaved $\alpha$-fodrinautoantigen is important because several researchers have detected homologous autoantibodies against this protein in primary and secondary SS patients and in murine models of SS [5]. The latter discovery, published in Scienceby Haneji et al in 1997, led to the elucidation of the nature of the autoantigen in the murine system and based upon the sequence, showed its homology with the human cytoskeletal protein, $\alpha$-fodrin. However, to our knowledge, our present study is the first to demonstrate the cleaved $120 \mathrm{kDa} \alpha$-fodrinautoantigen 
Citation: Yan Wang, Sean Parsel, Alexander Shnyra, Nicole Parrish, Kyle Boyce, Ying Liu and Carole McArthur (2016) A-fodrinAutoantigen Detection in Saliva and on Salivary Ductal Cells in Sjögren Syndrome. J. Dent. Sci. Ther 1(2): 5-14. doi: https://doi.org/10.24218/jdst.2016.07.

in human salivary glands and its secretions. Previous studies by our group have shown that salivary ductal and acinar cells strongly express cleaved $\alpha$-fodrin during apoptosis of salivary ductal and acinar cells in vitro. Several well-known autoantigens, including SS-A/SS-B, caspase 3, and $\alpha$-fodrin are cleaved during apoptosis and transported to the cell surface [10].Collectively, these results point to a strong association between cleaved $\alpha$-fodrin and other markers of autoimmune disease known to play a role in apoptosis such as SS-A, SS-B and activated caspase-3 also confirmed by our group by DNA fragmentation [7].

As stated earlier, in an in vitromodel using HSG cells that $\alpha$-fodrin, caspase-3, poly(ADP-ribose) polymerase protease (PARP), SS-A, and SS-B were all cleaved in response to stimulation by TNF- $\alpha$, a known inducer of apoptosis [21].Therefore, it is possible that TNF, which is increased systemically in SS, contributes in vivo to apoptosis and destruction of salivary gland tissue. TNF- $\alpha$ and other cytokines such as IFN- $\gamma$ are known to be increased in vivoin the parenchyma of salivary and lacrimal glands of patients with SS [22-26].The cellular source of TNF in the salivary glands is unknown, however, although it is presumably released by infiltrating CD4 lymphocytes. Interestingly, all proteins except PARP are cleaved in vitroand transported to the ductal or acinar cell membrane; PARP, however, is cleaved but remains in the intracellular space [21].Perhaps this intracellular location of PARP where it appears protected from antigen processing by the immune system, is one factor contributing to why PARP is infrequently associated with autoantibody production in SS.

Haneji et al. first reported the presence of a $120 \mathrm{kDa}$ organspecific $\alpha$-fodrinautoantigen in a study of murine tissues. This antigen was purified from salivary gland tissues in the NFS/sld mouse model of human SS and the amino-terminal residues of the detected antigen were found to be identical to those reported for human $\alpha$-fodrin protein [5].This purified antigen was shown to induce proliferation of murine $\mathrm{T}$ cell responses in this same murine model of SS. Secondly, in the same report, ninety-five percent of sera from patients with SS examined reacted positively with purified $a$-fodrinautoantigen and recombinant human $\alpha$-fodrin protein providing the first evidence for a novel murine autoantigen with the homologous autoantibody occurring in humans with autoimmune diseases. There have been several controversial studies, where the specificity of the serologic response to $\alpha$-fodrin has been unclear. Some reports from studies on serum or plasma from patients with secondary SS, accompanied by systemic lupus erythematosus or rheumatoid arthritis, suggested they do not contain autoantibodies while other studies in secondary SS reported they were detected. The reason for these discrepancies may be in the characterization of patients or technological differences.

Preliminary evidence suggests that the $120 \mathrm{kDa}$ cleaved a-fodrin fragment may be important in stimulating the initial development of autoantibodies in vivo. Anti-cleaved a-fodrin (Asp 1185) antibody is a reagent, which only reacts with the $120 \mathrm{kDa}$ cleaved $\alpha$-fodrin fragment but not with intact fodrin antigen. The application of this antibody to detect the cleaved $\alpha$-fodrin products in labial salivary glands and saliva of patients with SS provides direct evidence that the cleaved $120 \mathrm{kDa}$ $\alpha$-fodrin fragment is produced by the same cells in salivary tissue during apoptosis since apoptosis and autoantigen co-expression has been shown by immunofluorescence [7].It is tempting to speculate that the cleaved $120 \mathrm{kDa}$ a-fodrin fragment is rendered immunogenic upon cleavage during apoptosis. Such cleaved products could then be presented to ductal epithelial or endothelial cells, which express HLA-DR antigens or CD40, and could then undergo antigen processing. This could result in an immune response with $\mathrm{T}$ cell proliferation and the production of the autoantibodies detected in many SS patients [21].This observation also provides a possible explanation for a central role of epithelial cells in SS implied by the location of the periductal and perivascular location of lymphocytic infiltrates in salivary gland ducts and vessels [21,27].It is interesting that cleaved PARP fragments have been reported on the ducts and acini but minimally detected in the area of the lymphocytic infiltrate compared with $\alpha$-fodrin [11]. This is consistent with the proposal that PARP, a nuclear antigen, we have shown is not expressed on the cell surface during apoptosis and therefore not expected to undergo antigen processing by infiltrating lymphocytes [7].

In contrast, Chen et al. assessed the existence of SS-A, SS-B, and $\alpha$-fodrin antigen in sera of individuals with primary SS, secondary SS, and non-Sjögrensicca syndrome (NSS). Using an ELISA, they showed, surprisingly, that the presence of serumafodrinautoantigen was more specific in patients with NSS versus primary and secondary SS [28].The authors suggested this could be an early marker of SS but at this time, a large group of patients with SS and NSS patients need to be followed to determine if the NSS group develop autoimmune SS. These authors did not examine saliva. Collectively, these observations suggest that the cleaved antigen fragment could be a marker for SS.

Autoantibodies against $\alpha$-fodrin have been found in many patients with primary and secondary SS; some of these patients lacked anti-SS-A antibodies in their serum [29,30]. Witte et al. further reported $\alpha$-fodrin autoantibodies as markers for SS in humans [31,32].Autoantibodies recognizing $a$-fodrin antigen was reported in another study in the serum of $95.3 \%$ of individuals with primary SS but not in patients with secondary SS or in healthy controls [5]. One of the objectives of this study was to determine the specificity of the relationship between the production of autoantibodies and the presence of the autoantigen in saliva but the data are limited and a much larger study is essential to elucidate this further. Previous clinical studies have shown circulating autoantibodies in SS patients. In one study, plasma autoantibodies were demonstrated in $20 \%$ of 200 patients with primary SS, with monoclonal IgG predominating [9]. While the measurement of anti- $\alpha$-fodrinIgG levels could only be performed in 17 out of 19 SS patients, 15 of these patients had IgG levels specific for $\alpha$-fodrin greater than those found in the unstimulated saliva of healthy patients. Interestingly, the levels of anti- $\alpha$-fodrin IgA detected in all 19 SS patients were 10 -fold lower than the reported value in normal individuals [10,33-35]. Explanations for this discrepancy in unexpectedly low $\operatorname{Ig} A$ values is unlikely to be due to collection, storage, and processing of samples as this was accomplished under identical conditions and at the same time as the controls. Possible explanations, however, include the presence of concomitant periodontal disease or immune complexes, which we did not examine, variations based in the degradation of IgA by bacterial proteases or binding of IgA to bacteria and loss during centrifugation. Moreover, in the presence of the cleaved antigen, autoantibodies could be blocked 
Citation: Yan Wang, Sean Parsel, Alexander Shnyra, Nicole Parrish, Kyle Boyce, Ying Liu and Carole McArthur (2016) A-fodrinAutoantigen Detection in Saliva and on Salivary Ductal Cells in Sjögren Syndrome. J. Dent. Sci. Ther 1(2): 5-14. doi: https://doi.org/10.24218/jdst.2016.07.

by homologous antigen and rendered undetectable. Finally, it could be due to low sensitivity of the ELISA or reduced saliva volume [36].

The current study has several limitations, some already discussed above. The detection of $\alpha$-fodrin by immunoblot involved only nine patients and a larger sample size would have conferred more power to the investigation. Likewise, our testing of IgG and IgA by ELISA was performed on a relatively small sample size. Despite this, our results show for the first time that the $120 \mathrm{kDa}$ fragment of $\alpha$-fodrin is a specific autoantigen present in the saliva of some patients with SS and worthy of further investigation. It would also be of interest to test lacrimal fluids for the presence of the autoantigen since lacrimal fluid, although of very small volume, is less complex and not compromised by the contents of the oral cavity and the multiple different glands that produce saliva as well as leakage via the gingival crevices. Multiple different aqueous or serous salivary glands, some of which require stimulation, make collection challenging and the resulting saliva complex. The discovery of cleaved $\alpha$-fodrin as a potential marker of disease in saliva could form the basis of a novel diagnostic test following confirmation using saliva and blood collected from patients in larger studies in SS and NSS patients and carried out over the course of the disease. The study could benefit from the application of a more sensitive technology given the difficulty in obtaining saliva in sufficient volumes from patients in advanced stages of disease. At present, there are no specific markers for Sjogren syndrome. Interleukin 6 (IL-6) has been suggested. However, IL-6 is only another nonspecific marker as higher IL-6 levels can also be present in many other inflammatory and autoimmune conditions [34,35].

\section{Conclusion}

The results of this study, carried out in well-characterized patients, support our hypothesis that $\alpha$-fodrin antigen is found in the saliva of primary SS patients and expressed on ductal epithelia; however, further studies are necessary to confirm these findings in a larger group of patients with primary and secondary SS representing all stages of disease. Further, we suggest that cleaved $\alpha$-fodrin may be a potential marker of primary Sjogren syndrome but emphasize the need for further studies that consider multiple autoantigens simultaneously. If these findings are confirmed, a sensitive diagnostic tool to detect cleaved $\alpha$-fodrin and possibly other autoantigens in saliva at an early stage of disease could be a useful adjunct to monitor disease progression and treat patients before exocrine destruction has occurred.

\section{Acknowledgement}

The authors would like to thank all of the participants for submitting samples for this study as well as the Arthritis Foundation for their financial support.

\section{References}

1. Fox RI, Howell FV, Bone RC, Michelson PE. Primary Sjogren syndrome: clinical and immunopathologic features. Semin Arthritis Rheum. 1984;14(2):77-105.

2. Ohlsson M, Skarstein K, Bolstad Al, Johannessen AC, Jonsson R. Fasinduced apoptosis is a rare event in Sjogren's syndrome. Lab Invest. 2001;81(1):95-105.
3. Bowman SJ, Ibrahim GH, Holmes G, Hamburger J, Ainsworth JR. Estimating the prevalence among Caucasian women of primary Sjögren's syndrome in two general practices in Birmingham, UK. Scand J Rheumatol. 2004; 33(1):39-43.

4. Cryns VL, Bergeron L, Zhu H, Li H, Yuan J. Specific cleavage of $\alpha$-fodrin during Fas- and tumor necrosis factor-induced apoptosis is mediated by an interleukin-1 $\beta$-converting enzyme/Ced-3 protease distinct from the poly(ADP-ribose) polymerase protease. J Biol Chem. 1996; 271(49):31277-82.

5. Haneji N, Nakamura T, Takio K, Yanagi K, Higashiyama H, Saito I, et al. Identification of $\alpha$-fodrin as a candidate autoantigen in primary Sjögren's syndrome. Science. 1997;276(5312):604-7.

6. Inoue H, Tsubota $K$, Ono M, Kizu Y, Mizuno F, Takada $K$, et al. Possible involvement of EBV-mediated alpha-fodrin cleavage for organ-specific autoantigen in Sjogren's syndrome. J Immunol. 2001; 166(9):5801-9.

7. McArthur $C$, Wang $Y$, Veno $P$, Zhang J, Fiorella R. Intracellular trafficking and surface expression of SS-A (Ro), SS-B (La), poly(ADPribose) polymerase and $\alpha$-fodrin autoantigens during apoptosis in human salivary gland cells induced by tumour necrosis factor- $\alpha$. Arch Oral Biol. 2002; 47(6):443-8.

8. McArthur CP, Africa CWJ, Castellani WJ, Luangjamekorn NJ, McLaughlin M, Subtil-DeOliveira A, et al. Salivary gland disease in HIV/AIDS and primary Sjögren's syndrome: analysis of collagen I distribution and histopathology in American and African patients. J Oral Pathol Med. 2003; 32(9):544-51.

9. Miyazaki K, Takeda N, Ishimaru N, Omotehara F, Arakaki R, Hayashi $\mathrm{Y}$. Analysis of in vivo role of alpha-fodrin autoantigen in primary Sjogren's syndrome. Am J Pathol. 2005;167(4):1051-9.

10. Wang Y, Virji AS, Howard P, Sayani Y, Zhang J, Achu P, et al. Detection of cleaved $\alpha$-fodrin autoantigen in Sjögren's syndrome: Apoptosis and co-localisation of cleaved $\alpha$-fodrin with activated caspase- 3 and cleaved poly(ADP-ribose) polymerase (PARP) in labial salivary glands. Arch Oral Biol. 2006; 51(7):558-66.

11. Bizzaro N, Villalta D, Tonutti E. Low sensitivity of anti-alphafodrin antibodies in patients with primary Sjögren's syndrome. J Rheumatol. 2004; 31(11):2310-1.

12. Jänicke RU, Ng P, Sprengart ML, Porter AG. Caspase-3 is required for alpha-fodrin cleavage but dispensable for cleavage of other death substrates in apoptosis. J Biol Chem. 1998; 273(25):15540-5.

13. Vitali $C$, Bombardieri $S$, Jonsson R, Moutsopoulos HM, Alexander $\mathrm{EL}$, Carsons SE, et al. Classification criteria for Sjögren's syndrome: a revised version of the European criteria proposed by the AmericanEuropean Consensus Group. Ann Rheum Dis. 2002; 61(6):554-8.

14. Nakamura H, Kawakami A, Yamasaki S, Nakashima T, Kamachi M, Migita $\mathrm{K}$, et al. Expression and function of $\mathrm{X}$ chromosome-linked inhibitor of apoptosis protein in Sjogren's Syndrome. Lab Invest. 2000; 80(9):1421-7.

15. Shirasuna K, Sato M, Miyazaki T. A neoplastic epithelial duct cell line established from an irradiated human salivary gland. Cancer. 1981; 48(3):745-52.

16. Sato M, Hayashi Y, Yoshida H, Yanagawa T, Yura Y, Nitta T. Search for specific markers of neoplastic epithelial duct and myoepithelial cell lines established from human salivary gland and characterization of their growth in vitro. Cancer. 1984; 54(12):2959-67.

17. Matsumura R, Umemiya K, Kagami M, Tomioka H, Tanabe E, Sugiyama $T$, et al. Expression of TNF-related apoptosis inducing ligand (TRAIL) on infiltrating cells and of TRAIL receptors on salivary glands in patients with Sjogren's syndrome. Clin Exp Rheumatol. 2002; 20(6):791-8. 
Citation: Yan Wang, Sean Parsel, Alexander Shnyra, Nicole Parrish, Kyle Boyce, Ying Liu and Carole McArthur (2016) A-fodrinAutoantigen Detection in Saliva and on Salivary Ductal Cells in Sjögren Syndrome. J. Dent. Sci. Ther 1(2): 5-14. doi: https://doi.org/10.24218/jdst.2016.07.

18. Li J, Ha YM, Ku NY, Choi SY, Lee SJ, Oh SB, et al. Inhibitory effects of autoantibodies on the muscarinic receptors in Sjogren's syndrome. Lab Invest. 2004; 84(11):1430-8.

19. Wei P, Li C, Qiang L, He J, Li Z, Hua H. Role of salivary anti-SSA/B antibodies for diagnosing primary Sjögren's syndrome. Medicina Oral, Patología Oral y Cirugía Bucal. 2015; 20(2):e156-e60.

20. Bok S, Pathan S, Wood AJ, Chen B, Mathai CJ, Gangopadhyay K, et al., editors. Highly sensitive plasmonic grating platform for the detection of a wide range of infectious diseases 2015 2015: IEEE.

21. Dimitriou ID, Kapsogeorgou EK, Moutsopoulos HM, Manoussakis MN. CD40 on salivary gland epithelial cells: high constitutive expression by cultured cells from Sjögren's syndrome patients indicating their intrinsic activation. Clin Exp Immunol.2002; 127(2):386-92.

22. Boumba D, Skopouli FN, Moutsopoulos HM. Cytokine mRNA expression in the labial salivary gland tissues from patients with primary Sjögren's syndrome. Br J Rheumatol. 1995; 34(4):326-33.

23. Fox PC, Brennan M, Sun PD. Cytokine expression in human labial minor salivary gland epithelial cells in health and disease. Arch Oral Biol. 1999; 44 (Suppl 1):S49-S52.

24. Grisius MM, Bermudez DK, Fox PC. Salivary and serum interleukin 6 in primary Sjogren's syndrome. J Rheumatol. 1997; 24(6):1089-91.

25. Skopouli FN, Moutsopoulos HM. Cytokines in Sjogren's syndrome. Ann Med Interne (Paris). 1995; 146(4):219-22.

26. Fox RI, Kang HI, Ando D, Abrams J, Pisa E. Cytokine mRNA expression in salivary gland biopsies of Sjögren's syndrome. J Immunol. 1994; 152(11):5532-9.

27. Ogawa $M$, Oshima $M$, Imamura A, Sekine $Y$, Ishida K, Yamashita $K$, et al. Functional salivary gland regeneration by transplantation of $a$ bioengineered organ germ. Nat Commun. 2013; 4.
28. Chen KS, Jiang MC, Li CJ, Liu OK, Tsai CS. Discrimination between Sjögren's and non-Sjögren's sicca syndrome by sialoscintigraphy and antibodies against alpha-fodrin and Ro/La autoantigens. J Int Med Res. 2009; 37(4):1088-96.

29. Harris AS, Croall DE, Morrow JS. The calmodulin-binding site in alpha-fodrin is near the calcium-dependent protease-I cleavage site. J Biol Chem. 1988; 263(30):15754-61.

30. Ruiz-TíScar JL, LÓPez-Longo FJ, SÁNchez-RamÓN S, SantamaríA B, Urrea R, CarreÑO L, et al. Prevalence of IgG anti- $\alpha$-fodrin antibodies in Sjogren's syndrome. Ann N Y Acad Sci. 2005; 1050(1):210-6.

31. Gumpel J, Hobbs J. Serum immune globulins in Sjögren's syndrome. Ann Rheum Dis. 1970; 29(6):681-3.

32. Witte T, Matthias T, Arnett FC, Peter HH, Hartung K, Sachse C, et al. IgA and IgG autoantibodies against alpha-fodrin as markers for Sjogren's syndrome. Systemic lupus erythematosus. J Rheumatol. 2000; 27(11):2617-20.

33. Čejka J, Mood DW, Kim CS. Immunoglobulin concentrations in sera of normal children: quantitation against an international reference preparation. Clin Chem. 1974; 20(6):656-9.

34. Hulkkonen J, Pertovaara M, Antonen J, Pasternack A, Hurme M. Elevated interleukin- 6 plasma levels are regulated by the promoter region polymorphism of the IL6 gene in primary Sjögren's syndrome and correlate with the clinical manifestations of the disease. Rheumatology (Oxford). 2001; 40(6):656-61.

35. Tishler M, Yaron I, Shirazi I, Yossipov Y, Yaron M. Increased salivary interleukin-6 levels in patients with primary Sjögren's syndrome. Rheumatol Int. 1999; 18(4):125-7.

36. Brandtzæg P. Secretory immunity with special reference to the oral cavity. J Oral Microbiol. 2013; 5. doi: 10.3402/jom.v5i0.20401. 